\title{
Dissolution rate enhancement of gliclazide by ordered mixing
}

\author{
VIKAS A. SAHARAN ${ }^{1 *}$ \\ PRATIM K. CHOUDHURY² \\ 1 Institute of Pharmaceutical Sciences \\ and Drug Research, Seth G.L. Bihani \\ S.D. College of Technical Education \\ Sri Ganganagar, Rajasthan, India \\ 2 Department of Pharmaceutical \\ Sciences, M.L. Sukhadia University \\ Udaipur, Rajasthan, India
}

\begin{abstract}
The poorly water soluble antidiabetic drug gliclazide was selected to study the effect of excipients on dissolution rate enhancement. Ordered mixtures of micronized gliclazide with lactose, mannitol, sorbitol, maltitol and sodium chloride were prepared by manual shaking of glass vials containing the drug and excipient(s). Different water soluble excipients, addition of surfactant and superdisintegrant, drug concentration and carrier particle size influenced the dissolution rate of the drug. Dissolution rate studies of the prepared ordered mixtures revealed an increase in drug dissolution with all water soluble excipients. The order of dissolution rate improvement for gliclazide was mannitol $>$ lactose $>$ maltitol $>$ sorbitol $>$ sodium chloride. Composite granules of the particle size range $355-710 \mu \mathrm{m}$ were superior in increasing the drug dissolution rate from ordered mixtures. Reducing the carrier particle size decreased the dissolution rate of the drug as well as the increase in drug concentration. Kinetic modeling of drug release data fitted best the Hixson-Crowell model, which indicates that all the ordered mixture formulations followed the cube root law fairly well.

Keywords: gliclazide, excipient, dissolution, solubility, ordered mixture
\end{abstract}

Ordered mixtures consist of adhering fine particles of a hydrophobic drug to the surface of larger particles of a water soluble carrier substance (1). Carrier particles dissolve in the presence of water, whereby adherent particles of the pharmaceutical substance disperse throughout the liquid. This eliminates the inherent tendency of hydrophobic drug particles to collect into not-readily dissolvable and dispersible aggregate. Literature reveals that various water soluble excipients such as lactose, mannitol, sorbitol and sodium chloride have been extensively used in preparation of ordered mixtures (1-3).

Gliclazide is 1-(3,3a,4,5,6,6a-hexahydro- $1 H$-cyclopenta[c]pyrrol-2-yl)-3-(4-methylphenyl)sulfonylurea with molecular mass of 323.41 (PubChem Database; http://pubchem. ncbi.nlm.nih.gov). Gliclazide is used for the treatment of type II non-insulin dependent

\footnotetext{
*Correspondence; e-mail: vikas.pharmaceutics@gmail.com
} 
diabetes mellitus. Values for clog $P$ [calculated $\log P]$ and $\log P[\log$ arithm of partition coefficient between $n$-octanol and water, i.e. $\left.\log \left(c_{\text {octanol }} / c_{\text {water }}\right)\right]$, for gliclazide are 1.09 and 1.97, respectively. Clog $P$ classifies the drug as BCS (Biopharmaceutics Classification System) class IV and $\log P$ values as BCS class II (TSRL Inc. BCS Classification System; http://69.20.123.154/services/bcs/search.cfm). $\mathrm{pK}$ a of gliclazide is 6.9 and intrinsic solubility ( $\log S_{\mathrm{O}}$, expressed as the average $\log$ molar concentration \pm 1 standard deviation) is $-4.07 \pm 0.03$ (4). The aqueous solubility of gliclazide at $37^{\circ} \mathrm{C}$ is $55 \mu \mathrm{g} \mathrm{mL}-1$ (5). It was of interest to improve its dissolution rate using the ordered mixing approach. Attempts have already been made to increase the solubility and dissolution rate of gliclazide with anionic and cationic surfactants (5), by preparing solid dispersions (6-8), in situ micronisation $(9,10)$, cogrinding (11) and complexation with cyclodextrins (12).

In the present work, water soluble excipients (lactose, mannitol, maltitol, sorbitol and sodium chloride), superdisintegrant (sodium starch glycolate, SSG) and surfactant (sodium lauryl sulphate, SLS) have been used to improve the dissolution rate of gliclazide in different formulations prepared by ordered mixing.

\section{EXPERIMENTAL}

\section{Materials}

Gliclazide was obtained as a gift sample from Ranbaxy Ltd., India. Lactose (Lactochem Fine Powder) was received as a gratis sample from Domo Holland, The Netherlands. Mannitol (Pearlitol 200 SD), maltitol (Maltisorb P90), sorbitol (Neosorb P60) and sodium starch glycolate (Glycolys LV) were obtained as gift samples from Roquette, India. Sodium chloride and sodium lauryl sulphate were procured from the Central Drug House, New Delhi, India.

\section{Methods}

Average particle size and size distribution of the drug. - Particle size and size distribution of gliclazide were determined by laser light diffraction. The equipment consisted of a Malvern Mastersizer 2000 (Malvern Instruments Ltd, UK) including a Scirocco 2000 module for dry measurement operating at $3 \times 10^{5}$ pascals air pressure for dispersion. It was established that sufficient dispersion of particles, but no milling, occurs at this level of air pressure. Evaluation of data was done by the Malvern software version 5.22 using the Fraunhofer approximation as the evaluation algorithm. Polystyrene latex particles were used as dispersion medium.

Preparation of composite carrier granules. - Lactose or mannitol or maltitol or sorbitol or sodium chloride, and/or sodium starch glycolate, and/or SLS were mixed in a blender (200 g working capacity, customized V blender, Shakti Engineering, Ahmedabad, India) for 30 minutes. Absolute ethanol was added to the powder mixture and the dough was screened through a sieve of aperture size $1000 \mu \mathrm{m}$ to obtain composite carrier granules; this was followed by drying. 
Mixing of composite carrier granules and gliclazide. - An ordered mixture of gliclazide (Table I) was prepared by placing the micronized drug between two layers of composite carrier granules in a borosilicate glass vial $(10 \mathrm{~mL})$ and shaking it vigorously by hand for $5 \mathrm{~min}$. This method was found to produce consistently good quality ordered mixtures when observed by photomicrographs and concentration uniformity was assessed by homogeneity studies. The procedure had the advantage that it caused no size reduction of the carrier during mixing.

Homogeneity of gliclazide in ordered mixtures. - The accurately weighed ordered mixture $(200 \mathrm{mg})$ was transferred to a volumetric flask $(10 \mathrm{~mL})$. The volume was made up to the mark with methanol and sonicated (Ultrasonicator 6.5L200H, PCI Analytics, India) for 30 minutes. Liquid samples were then centrifuged. Supernatant aliquot ( $500 \mu \mathrm{L})$ was then diluted with distilled water to $10 \mathrm{~mL}$ and absorbance was measured at $\lambda_{\max } 226 \mathrm{~nm}$ (Pharmaspec UV-1700, Shimadzu, Japan). The concentration was read off from the standard curve.

Table I. Gliclazide ordered mixture formulations, dissolution after 5 and 10 minutes

\begin{tabular}{llcccccc}
\hline \multirow{2}{*}{ Formulation } & $\begin{array}{c}\text { Water } \\
\text { soluble } \\
\text { excipient }\end{array}$ & $\begin{array}{c}\text { Superdisin- } \\
\text { tegrant } \\
(8 \%, m / m)\end{array}$ & $\begin{array}{c}\text { Surfactant } \\
(1 \%, m / m)\end{array}$ & $\begin{array}{c}\text { Powder } \\
\text { fraction } \\
(\mu \mathrm{m})\end{array}$ & $\begin{array}{c}\text { concentration } \\
(\%, m / m)\end{array}$ & \multicolumn{2}{c}{\begin{tabular}{c} 
Dissolution $(\%)^{\mathrm{a}}$ \\
\cline { 5 - 9 }
\end{tabular}} \\
\hline GLF1 & Lactose & - & - & $125-710$ & 5 & $73.6 \pm 1.3$ & $85.4 \pm 1.4$ \\
GLF2 & Lactose & SSG & - & $125-710$ & 5 & $85.1 \pm 0.9$ & $92.5 \pm 1.6$ \\
GLF3 & Lactose & - & SLS & $125-710$ & 5 & $71.8 \pm 1.1$ & $85.3 \pm 1.5$ \\
GLF4 & Lactose & SSG & SLS & $125-710$ & 5 & $88.3 \pm 1.3$ & $96.8 \pm 0.9$ \\
GLF5 & Lactose & SSG & SLS & $355-710$ & 5 & $82.4 \pm 1.1$ & $88.3 \pm 1.4$ \\
GLF6 & Lactose & SSG & SLS & $250-355$ & 5 & $77.8 \pm 1.3$ & $84.9 \pm 0.9$ \\
GLF7 & Lactose & SSG & SLS & $180-250$ & 5 & $73.5 \pm 1.5$ & $80.7 \pm 1.1$ \\
GLF8 & Lactose & SSG & SLS & $150-180$ & 5 & $72.7 \pm 1.5$ & $80.2 \pm 1.1$ \\
GLF9 & Lactose & SSG & SLS & $125-710$ & 1 & $83.8 \pm 1.4$ & $95.5 \pm 1.2$ \\
GLF10 & Lactose & SSG & SLS & $125-710$ & 7 & $83.6 \pm 1.8$ & $94.4 \pm 1.4$ \\
GLF11 & Lactose & SSG & SLS & $125-710$ & 10 & $61.9 \pm 1.0$ & $79.2 \pm 1.0$ \\
GMF1 & Mannitol & - & - & $125-710$ & 5 & $82.7 \pm 1.3$ & $92.4 \pm 1.4$ \\
GMF2 & Mannitol & SSG & - & $125-710$ & 5 & $87.4 \pm 1.0$ & $94.4 \pm 1.6$ \\
GMF3 & Mannitol & - & SLS & $125-710$ & 5 & $83.6 \pm 1.1$ & $94.7 \pm 1.5$ \\
GMF4 & Mannitol & SSG & SLS & $125-710$ & 5 & $88.8 \pm 1.0$ & $96.0 \pm 0.8$ \\
GMF5 & Mannitol & SSG & SLS & $355-710$ & 5 & $88.1 \pm 1.3$ & $94.7 \pm 0.9$ \\
GMF6 & Mannitol & SSG & SLS & $250-355$ & 5 & $80.5 \pm 1.6$ & $88.3 \pm 1.3$ \\
GMF7 & Mannitol & SSG & SLS & $180-250$ & 5 & $80.3 \pm 1.5$ & $89.2 \pm 1.0$ \\
GMF8 & Mannitol & SSG & SLS & $150-180$ & 5 & $77.5 \pm 1.0$ & $87.1 \pm 0.8$ \\
GMF9 & Mannitol & SSG & SLS & $125-710$ & 1 & $86.5 \pm 1.4$ & $91.6 \pm 1.3$ \\
& & & & & & &
\end{tabular}




\begin{tabular}{|c|c|c|c|c|c|c|c|}
\hline GMF10 & Mannitol & SSG & SLS & $125-710$ & 7 & $83.9 \pm 2.0$ & $94.6 \pm 1.5$ \\
\hline GMF11 & Mannitol & SSG & SLS & $125-710$ & 10 & $60.7 \pm 1.0$ & $78.3 \pm 1.0$ \\
\hline GSF1 & Sorbitol & - & - & $125-710$ & 5 & $65.6 \pm 1.4$ & $77.5 \pm 1.4$ \\
\hline GSF2 & Sorbitol & SSG & - & $125-710$ & 5 & $72.6 \pm 1.4$ & $83.1 \pm 1.2$ \\
\hline GSF3 & Sorbitol & - & SLS & $125-710$ & 5 & $69.1 \pm 0.9$ & $80.8 \pm 1.6$ \\
\hline GSF4 & Sorbitol & SSG & SLS & $125-710$ & 5 & $87.4 \pm 1.0$ & $94.3 \pm 0.8$ \\
\hline GSF5 & Sorbitol & SSG & SLS & $355-710$ & 5 & $85.6 \pm 1.5$ & $92.8 \pm 1.0$ \\
\hline GSF6 & Sorbitol & SSG & SLS & $250-355$ & 5 & $77.7 \pm 1.4$ & $87.7 \pm 1.1$ \\
\hline GSF7 & Sorbitol & SSG & SLS & $180-250$ & 5 & $75.6 \pm 1.5$ & $84.9 \pm 1.0$ \\
\hline GSF8 & Sorbitol & SSG & SLS & $150-180$ & 5 & $70.9 \pm 1.3$ & $79.9 \pm 1.0$ \\
\hline GSF9 & Sorbitol & SSG & SLS & $125-710$ & 1 & $88.4 \pm 1.4$ & $98.3 \pm 1.2$ \\
\hline GSF10 & Sorbitol & SSG & SLS & $125-710$ & 7 & $82.9 \pm 1.8$ & $94.0 \pm 1.4$ \\
\hline GSF11 & Sorbitol & SSG & SLS & $125-710$ & 10 & $61.2 \pm 1.0$ & $78.8 \pm 1.0$ \\
\hline GMTF1 & Maltitol & - & - & $125-710$ & 5 & $68.9 \pm 1.3$ & $80.8 \pm 1.4$ \\
\hline GMTF2 & Maltitol & SSG & - & $125-710$ & 5 & $71.5 \pm 1.2$ & $85.2 \pm 1.4$ \\
\hline GMTF3 & Maltitol & - & SLS & $125-710$ & 5 & $73.9 \pm 1.1$ & $85.8 \pm 1.5$ \\
\hline GMTF4 & Maltitol & SSG & SLS & $125-710$ & 5 & $82.6 \pm 1.1$ & $92.7 \pm 0.8$ \\
\hline GMTF5 & Maltitol & SSG & SLS & $355-710$ & 5 & $82.2 \pm 1.3$ & $91.4 \pm 0.9$ \\
\hline GMTF6 & Maltitol & SSG & SLS & $250-355$ & 5 & $75.1 \pm 1.6$ & $85.0 \pm 1.2$ \\
\hline GMTF7 & Maltitol & SSG & SLS & $180-250$ & 5 & $72.6 \pm 1.5$ & $83.5 \pm 1.0$ \\
\hline GMTF8 & Maltitol & SSG & SLS & $150-180$ & 5 & $70.4 \pm 0.5$ & $81.9 \pm 0.8$ \\
\hline GMTF9 & Maltitol & SSG & SLS & $125-710$ & 1 & $85.3 \pm 1.4$ & $91.0 \pm 1.5$ \\
\hline GMTF10 & Maltitol & SSG & SLS & $125-710$ & 7 & $81.3 \pm 4.0$ & $92.5 \pm 3.2$ \\
\hline GMTF11 & Maltitol & SSG & SLS & $125-710$ & 10 & $61.2 \pm 1.0$ & $78.5 \pm 0.9$ \\
\hline GSCF1 & $\mathrm{NaCl}$ & - & - & $125-710$ & 5 & $29.9 \pm 0.8$ & $45.7 \pm 0.8$ \\
\hline GSCF2 & $\mathrm{NaCl}$ & SSG & - & $125-710$ & 5 & $38.7 \pm 2.1$ & $55.0 \pm 1.2$ \\
\hline GSCF3 & $\mathrm{NaCl}$ & - & SLS & $125-710$ & 5 & $32.4 \pm 0.6$ & $48.7 \pm 0.9$ \\
\hline GSCF4 & $\mathrm{NaCl}$ & SSG & SLS & $125-710$ & 5 & $43.5 \pm 1.5$ & $66.7 \pm 1.1$ \\
\hline GSCF5 & $\mathrm{NaCl}$ & SSG & SLS & $355-710$ & 5 & $42.6 \pm 1.3$ & $60.7 \pm 0.9$ \\
\hline GSCF6 & $\mathrm{NaCl}$ & SSG & SLS & $250-355$ & 5 & $38.2 \pm 0.9$ & $61.5 \pm 0.8$ \\
\hline GSCF7 & $\mathrm{NaCl}$ & SSG & SLS & $180-250$ & 5 & $23.9 \pm 1.2$ & $35.8 \pm 0.9$ \\
\hline GSCF8 & $\mathrm{NaCl}$ & SSG & SLS & $150-180$ & 5 & $21.2 \pm 1.5$ & $30.7 \pm 1.1$ \\
\hline GSCF9 & $\mathrm{NaCl}$ & SSG & SLS & $125-710$ & 1 & $48.9 \pm 1.4$ & $70.1 \pm 1.2$ \\
\hline GSCF10 & $\mathrm{NaCl}$ & SSG & SLS & $125-710$ & 7 & $38.2 \pm 1.8$ & $54.0 \pm 1.4$ \\
\hline GSCF11 & $\mathrm{NaCl}$ & SSG & SLS & $125-710$ & 10 & $30.0 \pm 1.0$ & $40.5 \pm 1.0$ \\
\hline Gliclazide & - & - & - & - & - & $10.9 \pm 1.4$ & $12.8 \pm 1.6$ \\
\hline $\begin{array}{l}\text { Gliclazide } \\
\text { suspension }\end{array}$ & - & - & - & - & - & $74.4 \pm 0.8$ & $76.5 \pm 0.9$ \\
\hline
\end{tabular}

a DP - cumulative percent drug release at a particular time, SLS - sodium lauryl sulphate, SSG - sodium starch glycolate 
Scanning electron microscopy (SEM). - Scanning electron microscopy was used to determine the surface coverage of carrier particles by gliclazide particles. A perfectly dried sample of powder or ordered mixture was mounted onto the stubs using double-sided adhesive tape. The mounted sample was coated with gold palladium alloy (150-200 10-8 m) using a fine coat ion sputter (Fine coat ion sputter, JFC-1100, Jeol, Japan). The samples were subsequently analyzed under the scanning electron microscope (JSM 6100, Jeol, Japan) for external morphology.

Dissolution studies of ordered mixtures. - Dissolution studies of gliclazide from ordered mixture and powdered samples were performed using the USP XXIV (13) paddle method (TDT-08L, Electrolab, India) at a stirring speed of $100 \mathrm{rpm}$ in distilled water. Samples of ordered mixture $(200 \mathrm{mg}$ ) were sequentially added to $900 \mathrm{~mL}$ of distilled water, covered and maintained at $37 \pm 0.5^{\circ} \mathrm{C}$. Aliquots of $5 \mathrm{~mL}$ were withdrawn and each time replaced with fresh medium. Obtained samples were analyzed for absorbance at $226 \mathrm{~nm}$. The univariate ANOVA was applied to the dissolution data at each time point using DDSolver (China Pharmaceutical University, Nanjing, China), which is an add-in Microsoft Excel added in program for modeling and comparison of dissolution profiles, to determine significant time $\times$ group interaction between formulations.

Dissolution studies of pure gliclazide and its suspension. - Pure gliclazide (aggregate form) and its suspension equivalent to the amount contained in ordered mixtures were also studied for drug release. Gliclazide suspension was prepared in distilled water containing $0.5 \%$ sodium lauryl sulphate and stirred for 5 minutes using a propeller mixer. All the dissolution studies were performed in the same manner as given under dissolution studies of ordered mixtures.

Mathematical modeling of release kinetics. - The in vitro drug release data were fitted to various release kinetic models (14), viz. zero-order kinetic model $M_{\mathrm{o}}-M_{\mathrm{t}}=k_{\mathrm{o}} t$, first-order model $\ln \left(M_{\mathrm{t}} / M_{\mathrm{o}}\right)=k_{1} t$, Higuchi model $M_{\mathrm{t}}=K \sqrt{t}$, Hixon-Crowell cube root model $\left(W_{\mathrm{o}}\right)^{1 / 3}-\left(W_{\mathrm{t}}\right)^{1 / 3}=k_{1 / 3} t$, where $M_{\mathrm{O}}, M_{\mathrm{t}}$ and $M_{\infty}$ correspond to the drug amount taken at zero time, dissolved at a particular time $(t)$ and at infinite $(\infty)$ time, respectively. The terms $W_{\mathrm{o}}$ and $W_{\mathrm{t}}$ refer to the mass of the drug taken initially and at time $t$, respectively. Various other terms, viz. $k_{\mathrm{O}}, k_{1}, k_{1 / 3}$ and $K$ refer to the release kinetic constants obtained from the linear curves of zero-order, first-order, Higuchi model and Hixson-Crowell cube root law, respectively.

\section{RESULTS AND DISCUSSION}

\section{Drug particle size, homogeneity of ordered mixtures, scanning electron micrographs}

Particle size of the drug plays an important role in formulations of poorly soluble drugs. Gliclazide in micronized form is used for the preparation of various ordered mixtures. The surface weighted mean diameter and volume weighted mean diameter of drug particles were 2.446 and $3.686 \mu \mathrm{m}$, respectively. The specific surface area of gliclazide drug particles was $2.34 \mathrm{~m}^{2} \mathrm{~g}^{-1}$. The homogeneity of the prepared ordered mixtures was estimated as RSD (\%) of their assay value, which were less than 3.5 for different formu- 

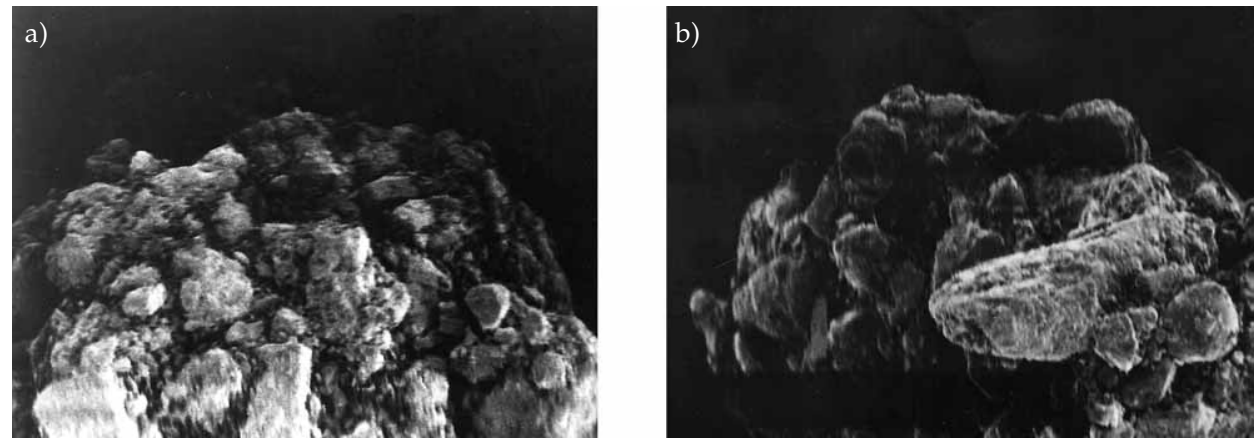

Fig. 1. Photomicrographs showing the surface of ordered mixtures of gliclazide with: (a) lactose, (b) mannitol.

lations (Table II). Scanning electron photomicrographs of gliclazide ordered mixtures with composite granules of lactose and mannitol are presented in Fig. 1. It seems rather difficult to identify drug particles lodged over the surface of composite granules. However, the presence of crevices and surface irregularities in photomicrographs are considered to be the potential sites where micronized gliclazide particles were lodged.

Table II. Homogeneity of gliclazide ordered mixtures

\begin{tabular}{cc}
\hline Formulation & Gliclazide $(\%)^{\mathrm{a}}$ \\
\hline GLF4 & $101.1 \pm 3.0$ \\
GMF4 & $100.8 \pm 2.0$ \\
GMTF4 & $101.5 \pm 3.0$ \\
GSF4 & $100.0 \pm 2.1$ \\
GSCF4 & $101.1 \pm 2.3$ \\
\hline
\end{tabular}

a Mean $\pm \mathrm{SD}, n=6$.

\section{Variables affecting gliclazide release from ordered mixtures}

Effect of formulation variables. - Gliclazide release from pure drug powder was 10.9 and $12.8 \%$ after 5 and 10 minutes, respectively, while the drug release from suspension was 74.4 and $76.5 \%$ after 5 and 10 minutes, respectively. All ordered mixture formulations increased the dissolution rate of gliclazide. The least increase in dissolution rate was observed with $\mathrm{NaCl}$ (Table I; GSCF1 to GSCF11). The order of the dissolution rate enhancement was mannitol $>$ lactose $>$ maltitol $>$ sorbitol $>$ sodium chloride (Table I). The dissolution rate of gliclazide from ordered mixtures containing sugar and sugars alcohols (Table I, GLF1-GLF11, GMF1-GMF11, GSF1-GSF11, GMTF1-GMTF11) was superior to gliclazide suspension at initial time points, i.e. 5 and 10 minutes. 
Addition of superdisintegrant SSG in granules (Table I, GLF1, GLF2, GMF1, GMF2, GSF1, GSF2, GMTF1, GMTF2, GSCF1, GSCF2) further contributed to the increase in gliclazide dissolution from ordered mixtures. Maximum increase of 11.5 and $7.0 \%$ after 5 and $10 \mathrm{~min}$, respectively, was oftained in GLF2 compared to the GLF1. The minimum effect of superdisintegrant addition of only $1.9 \%$ after 10 minutes was observed in GMF2. Superdisintegrant swells at a rapid rate and thereby disintegrates the granule so that carrier particles dissolve at a faster rate, which further increases the ability of the composite granule to release the individual, mutually discrete primary gliclazide particles. Surfactants in the range of $0.5-3 \%$ by mass of the ordered mixture have been suggested to improve the dissolution of hydrophobic drugs (15). In our studies, a very slight increase of $0-5 \%$ in dissolution rate was observed (Table I, GLF1, GLF3, GMF1 GMF3, GSF1, GSF3, GMTF1, GMTF3, GSCF1, GSCF3). When both superdisintegrant and surfactant were added to a composite granule, the synergistic effect of $6-17 \%$ increase of dissolution rate after 10 minutes was observed (Table I, GLF1, GLF4, GMF1, GMF4, GSF1, GSF4, GMTF1, GMTF4, GSCF1, GSCF4). The synergistic increase in dissolution (GMF4 vs. GMF1) was minimum with mannitol, 6.2 and $3.6 \%$ after 5 and $10 \mathrm{~min}$, respectively. This was due to the very fast drug release with mannitol in the GMF1 formulation.

Effect of carrier particle size. - The coarsest granule fraction (average particle size $532.5 \mu \mathrm{m}$ ) was most effective in improving the dissolution of gliclazide with all the carriers (Table I, GLF6, GMF6, GSF6, GMTF6, GSCF6). The fine particle size of the composite carrier granule decreased the dissolution rate (Table I) with all the carriers. In sodium chloride ordered mixtures, the effect of particle size on the dissolution rate was comparatively higher (Table I, GSCF5-GSCF8). The fine ordered mixture (150-180 $\mu \mathrm{m}, \mathrm{GSCF8})$ released about $30.7 \%$ drug while the coarser ordered mixture (355-710 $\mu \mathrm{m}$, GSCF5) released $60.7 \%$ drug in 15 minutes, which was a twofold increase. Coarser particles show a greater tendency to deviate from spherical size and possess cavities, capillaries and crevices, which increases the chances of adhesion of fine drug particles on the surface. This effect may affect the homogeneity of the formulation. Polydisperse carrier particles (125-710 $\mu \mathrm{m}$, GLF4, GMF4, GSF4, GMTF4, GSCF4), mixtures of all size ranges of particles, were equally effective as the coarsest size composite particles in improving the dissolution rate (Table I). This is presumably due to the effect of fine particles present along with the coarse carrier particles.

Effect of drug concentration. - The ordered mixture with 1 and $5 \%(\mathrm{~m} / \mathrm{m})$ gliclazide gave higher dissolution of gliclazide (Table I, GLF9, GLF4, GMF9, GMF4, GSF9, GSF4, GMTF9, GMTF4, GSCF9, GSCF4) than the formulations containing higher drug concentrations (7 and $10 \%, \mathrm{~m} / \mathrm{m}$ ) (Table I, GLF10, GLF11, GMF10, GMF11, GSF10, GSF11, GMTF10, GMTF11, GSCF10, GSCF11). When different ordered mixture formulations were compared for a change in the drug dissolution rate after 10 minutes with the increase of drug concentration from 1 to $10 \%(\mathrm{~m} / \mathrm{m})$, it was found that the decrease was $16.4,13.3$, 20.1, 12.3 and $29.7 \%$ with lactose, mannitol, sorbitol, maltitol and sodium chloride containing ordered mixtures respectively. At higher drug concentrations, $7 \%(\mathrm{~m} / \mathrm{m})$ or more, uneven coatings and loadings above monolayer coverage of hydrophobic drug particles reduced the drug dissolution rates due to incomplete drug deagglomeration and carrier solubilization. Dissolution rate of ordered mixtures with gliclazide concentration of 1,5 and $7 \%(\mathrm{~m} / \mathrm{m})$ was faster than gliclazide suspension. Drug concentration of $10 \%(\mathrm{~m} / \mathrm{m})$, 
in ordered mixtures of sugar and sugar alcohols, decreased the dissolution rate, which approached the release rate of drug suspension. In case of ordered mixtures of gliclazide and sodium chloride, the dissolution rate of gliclazide was even lower than that of the drug suspension (Table I).

Mathematical modeling of release kinetics. - The regression parameters obtained after fitting various release kinetic models to the in vitro dissolution data are listed in Table III. After fitting these models to the dissolution data of formulations, the selection was based on comparison of higher determination coefficients. Drug release kinetics for ordered mixtures fitted best the Hixson-Crowell model. Ordered mixtures disintegrated rapidly, followed by quick dissolution of water soluble excipients (lactose, mannitol, sorbitol, maltitol and sodium chloride), thereby forming a drug suspension consisting of discrete primary drug particles. Wetting of hydrophobic drug particles was further aided by the presence of surfactant, which also reduced aggregation. Surface specific dissolution rate increased as the particle size of hydrophobic drugs decreased, especially for micronized drugs. The dissolution rate enhancement was anticipated due to the rapid decrease in thickness of the stagnant diffusion layer around micronized drug particles. Small diffusion boundary layer thickness resulted in faster transport of dissolved molecules from the particle surface. Therefore, it was anticipated that all the ordered mixture formulations followed the cube root law enunciated by Hixson-Crowell.

Table III. Regression parameters of selected formulations after fitting the drug release data to various release kinetics models

\begin{tabular}{lcccc}
\hline \multirow{2}{*}{ Formulation } & \multicolumn{3}{c}{$R^{2}$} \\
\cline { 2 - 5 } & Zero-order & First-order & Higuchi & Hixson-Crowell \\
\hline GLF4 & 0.519 & 0.801 & 0.683 & 0.956 \\
GMF4 & 0.608 & 0.915 & 0.768 & 0.972 \\
GSF4 & 0.404 & 0.588 & 0.57 & 0.968 \\
GMTF4 & 0.545 & 0.695 & 0.714 & 0.988 \\
GSCF4 & 0.77 & 0.987 & 0.901 & 0.986 \\
\hline
\end{tabular}

Comparison of dissolution data. - The dissolution rate of glicazide from pure drug powder was extremely slow. Increase of 3.2 to 7.7 fold in cumulative percent drug release from ordered mixtures after 10 minutes (Table I) was observed. On the basis of cumulative percent dissolution and dissolution efficiency data (Table IV), the order of dissolution rate enhancement with various ordered mixtures was: mannitol (GMF4) > lactose $($ GLF4) > maltitol $($ GMTF4) > sorbitol $($ GSF4) $>\mathrm{NaCl}$ (GSCF4). The relative dissolution rate $(R D r)$ of different formulations to gliclazide alone indicated that all sugar and sugar alcohols were equally effective in increasing the dissolution rate up to 30 minutes.

The results of univariate ANOVA (Table IV) showed that the cumulative percent drug dissolved was significantly different at each time point for different formulations, so time $\times$ group interactions were found to be significant in all formulations $(p<0.05)$ com- 
a)

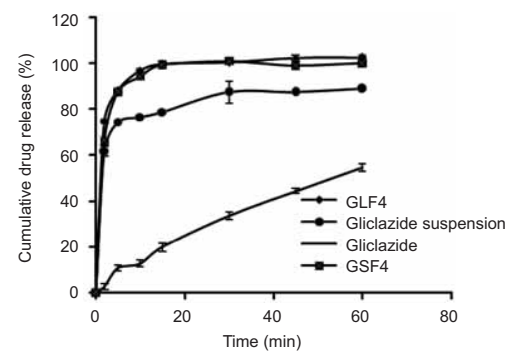

b)

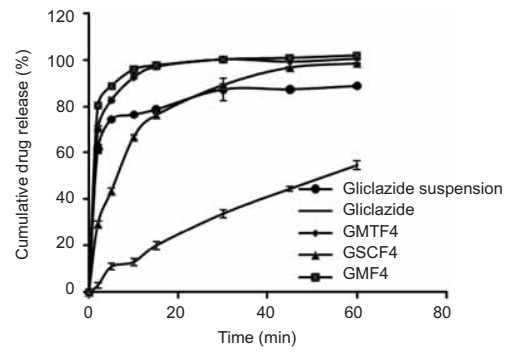

Fig. 2. Dissolution profiles of gliclazide alone and some selected ordered mixture formulations: a) GLF4, GSF4; b) GMF4, GSCF4, GMTF4. Mean \pm SD, $n=3$.

pared to the glicazide suspension, i.e., dissolved was the dissolution profiles were not parallel and ordered mixtures had improved the dissolution rate of gliclazide.

When the ordered mixture formulations were compared to the GMF4 formulation $(p<0.05)$ by univariate ANOVA, the percent drug dissolved from GLF4 and GSF4 were found not significantly different after the second minute while that from GMTF4 was not significantly different after ten minutes. It was also observed that the percent drug dissolved for GSCF4 showed lower release than the other formulations. Differences between GSCF4 and the reference GMF4 were also significant $(p<0.001)$ at all time points (Fig. 2 and Table IV) which means that dissolution profiles were not parallel.

Table IV. Dissolution parameters of various ordered mixtures

\begin{tabular}{lcccccc}
\hline \multirow{2}{*}{ Formulation } & \multicolumn{5}{c}{ Dissolution parameter } \\
\cline { 2 - 7 } & $D P_{2 \min }(\%)$ & $D P_{10 \min }(\%)$ & $D P_{60 \min }(\%)$ & $D E_{5 \min }(\%)$ & $D E_{15 \min }(\%)$ & $R D r_{30} \min (\%)$ \\
\hline GMF4 & $80.54^{\mathrm{b}}$ & $96.02^{\mathrm{b}}$ & $102.02^{\mathrm{b}}$ & 85.38 & 96.73 & 2.96 \\
GLF4 & $74.54^{\mathrm{a}, \mathrm{b}}$ & $96.75^{\mathrm{b}}$ & $102.54^{\mathrm{b}}$ & 81.67 & 97.49 & 2.96 \\
GSF4 & $66^{\mathrm{a}, \mathrm{b}}$ & $94.31^{\mathrm{b}}$ & $100.08^{\mathrm{b}}$ & 78.8 & 98.57 & 2.98 \\
GMTF4 & $70.15^{\mathrm{a}, \mathrm{b}}$ & $92.69^{\mathrm{a}, \mathrm{b}}$ & $100.75^{\mathrm{b}}$ & 78.05 & 96.03 & 2.96 \\
GSCF4 & $29.38^{\mathrm{a}, \mathrm{b}}$ & $66.71^{\mathrm{a}, \mathrm{b}}$ & $98.52^{\mathrm{a}, \mathrm{b}}$ & 37.74 & 73.6 & 2.64 \\
Gliclazide & 61.69 & 76.52 & 88.86 & 70.49 & 79.59 & 2.58 \\
suspension & 61.5 & & & & & \\
\hline
\end{tabular}

$D P$ - Cumulative percent drug release at a particular time.

$D E$ (\%): Dissolution efficiency at a particular time. Dissolution efficiency (\%) up to $5 \mathrm{~min}\left(D E_{5 \mathrm{~min}}\right)$ and 15 minutes $\left(D E_{15 \mathrm{~min}}\right)$ were calculated according to the following equation: $D E \%=\frac{\int_{0}^{t} y d t}{y_{100} t} \times 100$

$R D r_{30 \text { min }}$ - Relative dissolution rate after 30 minutes, i.e., ratio of cumulative percent drug release from formulation at 30 minute to cumulative percent drug released from pure drug.

a Significant difference in cumulative percent drug release between the formulation and GMF4 formulation by univariate ANOVA, at the same time point; $p<0.05$.

$\mathrm{b}$ Significant difference in cumulative percent drug release between the formulation and gliclazide suspension by univariate ANOVA, at the same time point, $p<0.05$. 
Higher dissolution rate of gliclazide in ordered mixtures was therefore attributed to improved wetting of the drug owing to attachment of smaller size drug particles over the surface of water soluble excipients, i.e., mannitol, lactose, etc. Mannitol and lactose thus physically separated drug particles, thereby preventing aggregation after introduction of ordered mixtures to the dissolution medium. Hydrophilic carriers are known to interact with drug molecules mainly by electrostatic forces and occasionally by other types of forces like hydrogen bonds but this phenomenon is drug- and excipient-specific. Mannitol and lactose thus incite a solubilizing effect. The difference in their ability of dissolution rate enhancement might be due to the difference in the solubilizing effect in the dissolution medium. Hydrophilic carriers attract the dissolution medium and increase its amount in the immediate vicinity of the gliclazide surface. Addition of surfactant, SLS, to the ordered mixture further aided the reduction of surface tension of the dissolution medium, thereby improving wetting and preventing aggregation of drug particles. Superdisintegrant, SSG, was helpful in disintegrating the granules and dispersing discrete drug particles in the entire dissolution medium, so that the system behaved like a well stirred aqueous dispersion.

\section{CONCLUSIONS}

Ordered mixtures of acceptable homogeneity can be prepared by simple manual mixing in a vial. Choice of carrier played an important role in improving gliclazide dissolution from prepared ordered mixtures. The order of dissolution rate enhancement of gliclazide from different ordered mixtures was: mannitol $>$ lactose $>$ maltitol $>$ sorbitol $>$ sodium chloride. Coarse granules of $355-710 \mu \mathrm{m}$ were more effective than fine particles in improving the gliclazide dissolution. Dissolution rate from ordered mixtures of gliclazide concentration 1,5 and $7 \%(\mathrm{~m} / \mathrm{m})$ were higher than the dissolution from gliclazide suspension. Hixson Crowell model described the drug release from ordered mixtures which was presumably due to surface specific drug dissolution from discrete primary drug particles in the dissolution medium.

Acknowledgements. - Vikas A. Saharan acknowledges the administrative and motivational support of Prof. (Dr.) Vipin Kukkar, Director/Principal, and Mr. Mahesh Kumar Kataria, Assistant Professor, at Seth G.L. Bihani S.D. College of Technical Education, Sri Ganganagar, Rajasthan, India.

\section{REFERENCES}

1. V. A. Saharan, V. Kukkar, M. Kataria, V. Kharb and P. Choudhury, Ordered mixing: mechanism, process and applications in pharmaceutical formulations, Asian J. Pharm. Sci. 3 (2008) 240-259.

2. V. A. Saharan, M. Kataria, V. Kukkar, M. Gera and P. K. Choudhury, Dissolution enhancement of drugs Part II: Effect of carriers, Int. J. Health Res. 2 (2009) 207-223.

3. V. A. Saharan, M. Kataria, V. Kukkar, M. Gera and P. K. Choudhury, Dissolution enhancement of drugs Part I: Technologies and effect of carriers, Int. J. Health Res. 2 (2009) 107-124.

4. C. M. Wassvik, A. G. Holmen, C. A. Bergstrom, I. Zamora and P. Artursson, Contribution of solid-state properties to the aqueous solubility of drugs, Eur. J. Pharm. Sci. 29 (2006) 294-305; DOI: $10.1016 /$ j.ejps.2006.05.013. 
5. H. Allaboun, K. A. Alkhamis and W. Y. AlMomani, The application of the convective diffusion model and the film equilibrium model to surfactant-facilitated dissolution of gliclazide, Eur. J. Pharm. Sci. 19 (2003) 231-236; DOI: 10.1016/S0928-0987(03)00107-6.

6. S. Biswal, J. Sahoo, P. N. Murthy, R. P. Giradkar and J. G. Avari, Enhancement of dissolution rate of gliclazide using solid dispersions with polyethylene glycol 6000, AAPS PharmSciTech 9 (2008) 563-570; DOI: 10.1208/s12249-008-9079-z.

7. S. Asyarie and H. Rachmawati, In vivo and in vitro evaluation of a solid dispersion system of gliclazide: PEG 6000, PDA J. Pharm. Sci. Technol. 61 (2007) 400-410.

8. M. P. Patil and N. J. Gaikwad, Preparation and characterization of gliclazide-polyethylene glycol 4000 solid dispersions, Acta Pharm. 59 (2009) 57-65; DOI: 10.2478/v10007-009-0001-3.

9. R. Talari, A. Nokhodchi, S. A. Mostafavi and J. Varshosaz, Dissolution enhancement of gliclazide using $\mathrm{pH}$ change approach in the presence of twelve stabilizers with various physico-chemical properties, J. Pharm. Pharm. Sci. 12 (2009) 250-265.

10. R. Talari, J. Varshosaz, S. A. Mostafavi and A. Nokhodchi, Gliclazide microcrystals prepared by two methods of in situ micronization: Pharmacokinetic studies in diabetic and normal rats, AAPS PharmSciTech 11 (2010) 786-792; DOI: 10.1208/s12249-010-9441-9.

11. M. Barzegar-Jalalia, H. Valizadeha, M.-R. S. Shadbada, K. Adibkiaa, G. Mohammadia, A. Farahania, Z. Arasha and A. Nokhodchi, Cogrinding as an approach to enhance dissolution rate of a poorly water-soluble drug (gliclazide), Powder Technol. 197 (2010) 150-158; DOI: 10.1016/j. powtec.2009.09.008.

12. Y. K. Lo, C. J. Chen, T. R. Tsai and T. M. Cham, Comparison of the solubility and dissolution rate between gliclazide solid complex and its nanospheres, Drug Dev. Ind. Pharm. 33 (2007) 301309; DOI: $10.1080 / 03639040600920622$.

13. United States Pharmacopeia XXIV, National Formulary XIX, USO Convention, Rockville (MD) 1999.

14. P. Costa and J. Lobo, Modeling and comparison of dissolution profiles, Eur. J. Pharm. Sci. 13 (2001) 123-133; DOI: 10.1016/S0928-0987(01)00095-1.

15. M. Westerberg and C. Nystrom, Physicochemical aspects of drug release. Part 18: Use of a surfactant and a disintegrant for improving drug dissolution rate from ordered mixtures, STPPharm Sci. 3 (1993) 142-147.

\section{$S A \check{Z} E T A K$}

\section{Povećanje oslobađanja gliklazida iz smjesa dobivenih geometrijskim miješanjem}

VIKAS A. SAHARAN i PRATIM K. CHOUDHURY

Teško topljivi antidijabetik gliklazid izabran je za proučavanje utjecaja pomoćnih tvari na povećanje oslobađanja. Homogene smjese mikroniziranog gliklazida s laktozom, manitolom, sorbitolom, maltitolom i natrijevim kloridom pripravljene su ručnim tresenjem staklenih bočica s lijekom i pomoćnom tvari/tvarima. Na oslobađanje lijeka utjecali su vrsta vodotopljivog ekscipijensa, dodatak surfaktanta i superdezintegratora, udio lijeka i veličina čestica punila. Sve vodotopljive pomoćne tvari povećavale su oslobađanje ljekovite tvari i to sljedećim redom: manitol $>$ laktoza $>$ maltitol $>$ sorbitol $>$ natrijev klorid. Najbolje oslobađanje lijeka bilo je iz kompozitnih granula veličine 355 do $710 \mu \mathrm{m}$. Iz smjesa s manjom veličinom čestica punila i većim udjelom lijeka oslobađanje lijeka bilo 
je manje. Kinetičko modeliranje oslobađanja najbolje je odgovaralo Hixson-Crowellovom modelu, što ukazuje na to da sve formulacije prilično dobro slijede zakon trećeg korijena.

Ključne riječi: gliklazid, ekscipijens, oslobađanje, topljivost, smjese dobivene geometrijskim miješanjem

Institute of Pharmaceutical Sciences and Drug Research, Seth G.L. Bihani S.D. College of Technical Education, Sri Ganganagar, Rajasthan, India

Department of Pharmaceutical Sciences, M.L. Sukhadia University, Udaipur, Rajasthan, India 